\title{
CHRONIC DISEASE AND INJURY INDICATOR FRAMEWORK QUICK STATS, 2016 EDITION
}

Y Tweet this article

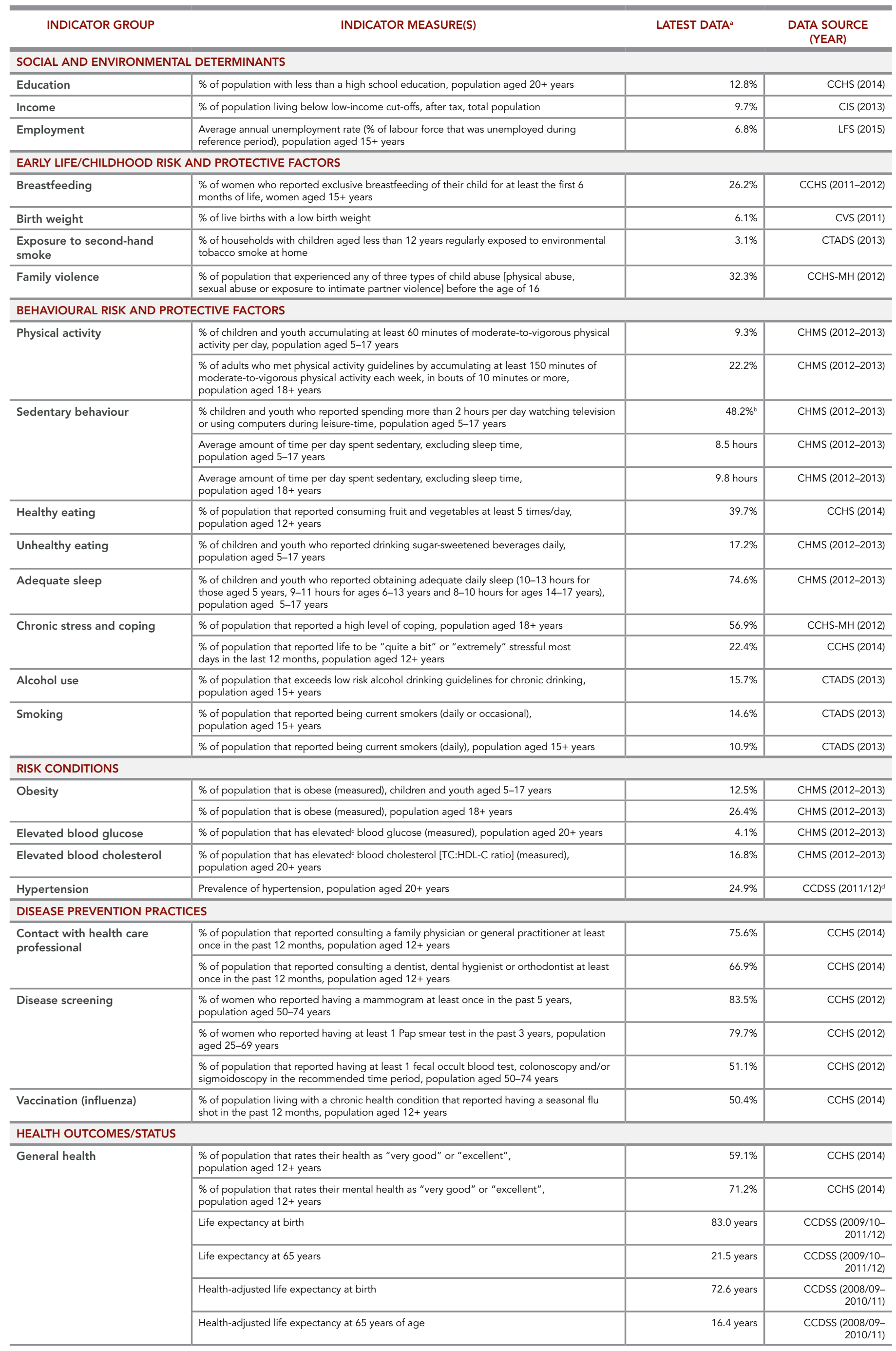




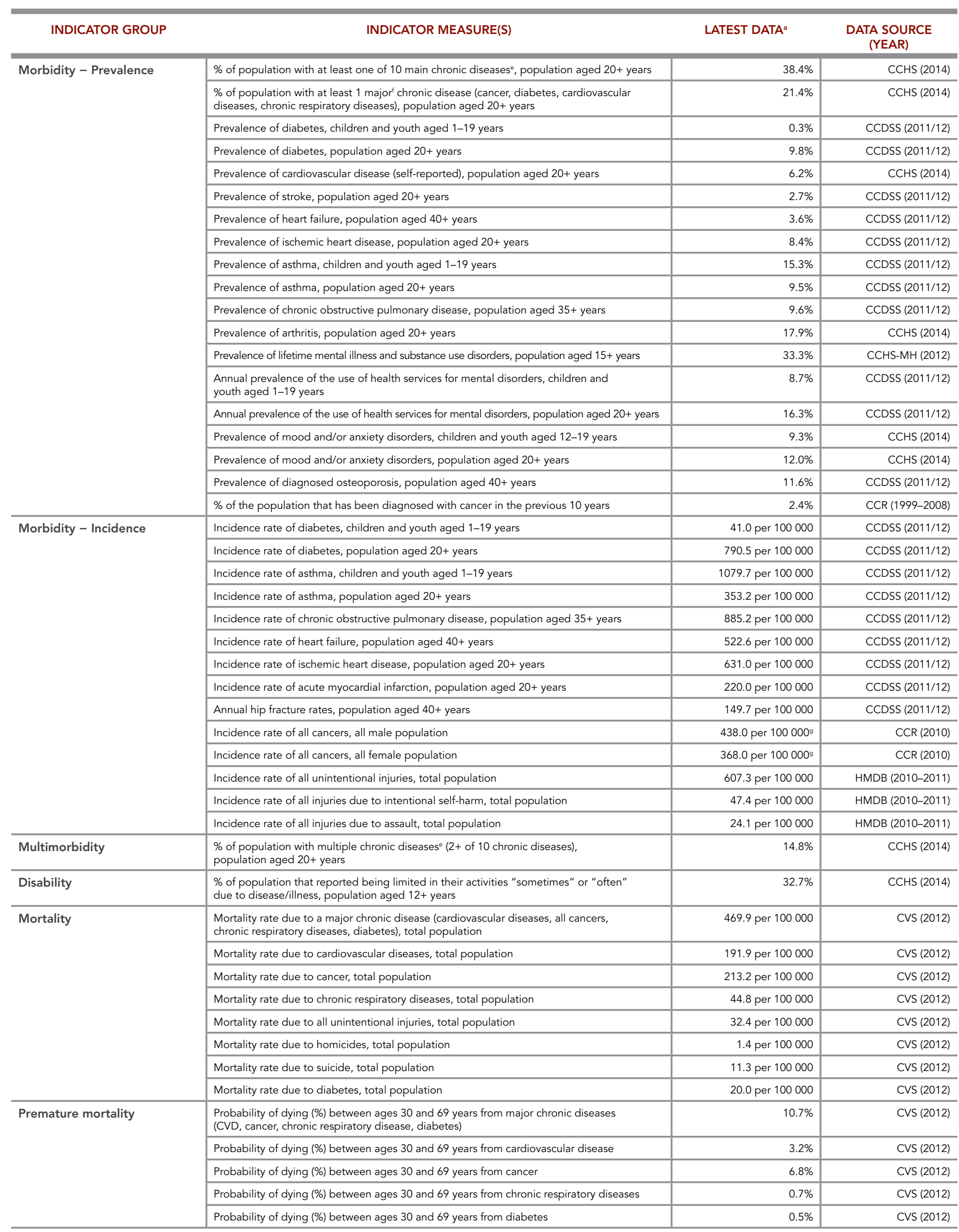

Abbreviations: CCDSS, Canadian Chronic Disease Surveillance System; CCHS, Canadian Community Health Survey; CCR, Canadian Cancer Registry; CHMS, Canadian Health Measures Survey; CIS, Canadian Income Survey; CTADS, Canadian Tobacco, Alcohol and Drugs Survey; CVD, cardiovascular disease; CVS, Canadian Vital Statistics; HDL-C, high-density lipoprotein cholesterol; HMDB, Hospital Morbidity Database; LFS, Labour Force Survey; MH, Mental Health; TC, total cholesterol.

a All pan-Canadian rates in this table are crude unless otherwise stated.

b The estimates for sedentary behaviour differ from those presented in the 2015 CDIIF due to an adjustment made to account for a change in variable formatting during the survey's data collection.

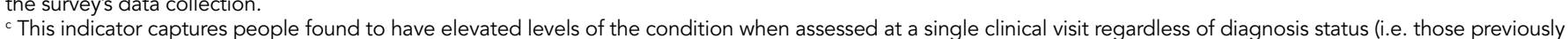
diagnosed and well controlled are not captured).

d CHMS data exist for this indicator presenting pan-Canadian rates according to diagnosis and control status of hypertension.

- The ten chronic diseases included are heart disease, stroke, cancer, asthma, chronic obstructive pulmonary disease, diabetes, arthritis, Alzheimer's or other dementia,

The ten chronic diseases included are hear

the four main groups of chronic diseases include cancer, diabetes, cardiovascular disease (heart disease and/or stroke), chronic respiratory diseases (asthma and/or The four main groups of chronic diseases

chronic obstructive pulmonary disease).
Rates are age-standardized to the 1991 Canadian population.

Correspondence: Surveillance and Epidemiology Division, Centre for Chronic Disease Prevention, Public Health Agency of Canada, 785 Carling Avenue, Ottawa, ON

K1A OK9: Tel: 613-291-6947; Email: Infobase@phac-aspc.gc.ca

Suggested Citation: Centre for Chronic Disease Prevention, Public Health Agency of Canada. Chronic Disease and Injury Indicator Framework: Quick Stats, 2016 Edition. Ottawa (ON): Public Health Agency of Canada; 2016.

Visit the Chronic Disease and Injury Indicator Framework's online tool to view additional data breakdowns: http://infobase.phac-aspc.gc.ca/cdiif 